\title{
On the origins of the anisotropic mechanical behaviour of extruded AA2017 aluminium alloy
}

\author{
A MAY (D) \\ Laboratoire Génie des Matériaux, Ecole Militaire Polytechnique, BP 17, Bordj El Bahri 16046, Algeria
}

MS received 20 January 2017; accepted 23 February 2017

\begin{abstract}
This paper presents some experimental investigations about the origins of the anisotropic behaviour in cyclic loadings of AA2017 aluminium alloy. In the first step, fatigue damage evolutions were quantified for controlled proportional cyclic loadings in axial and shear directions. In this stage, the aim was to confirm the anisotropic mechanical behaviour, which has recently been revealed. To this end, several models of fatigue damage quantification were used. After a comparative study between the obtained results we confirmed the anisotropic nature of the used material. In the second step, microstructural investigations were performed in order to understand the origins of the anisotropic mechanical behaviour. We used scanning electron microscopy to analyse phases and precipitates in the transversal and the longitudinal sections. It was deduced that the structure and the morphology of these entities are responsible for the anisotropic behaviour of the used aluminium alloy. Moreover, the results obtained using Kikushi diagrams, poles figure and inverse poles figures have also confirmed these conclusions. Indeed, these results have shown great differences in crystallographic texture of the material.
\end{abstract}

Keywords. Anisotropic behaviour; extruded aluminium alloy; fatigue damage; microstructures; EBSD and Kikushi diagrams.

\section{Introduction}

The use of the aluminium alloys in aeronautical applications has become increasingly important, due to its useful mechanical properties associated with low density and good fracture toughness [1-3]. Therefore, the AA2017 aluminium alloy is currently being employed as the principal metallic material in all the structures of planes [4-7]. Most engineering structures are subjected to hard cyclic loading $[8,9]$. Consequently, mechanical fatigue damage is one of the main forms of failure in engineering structures. Hence, it is important to formulate a method for the assessment of reliability and prediction of engineering components [10-13]. Many studies, such as the work of Mayer et al [14], showed that fatigue performances of some materials for instance $\mathrm{AlZnMgCu} 1.5$ aluminium alloy, were insensitive to loading frequency, whereas Kofto showed that some other aluminium alloys, such as $\mathrm{AMg}_{6} \mathrm{~N}$, exhibited significant frequency-dependent fatigue behaviours [15]. For this kind of aluminium alloys, ignoring the influence of loading frequency on fatigue life can lead to significant waste of the materials or potential dangerous overprediction of fatigue life [10]. In the recent work by May et al [16], they concluded that the AA2017 aluminium alloy exhibited an anisotropic cyclic behaviour. Furthermore, the same authors have estimated the evolution of cyclic isotropic

abdelghani1980@yahoo.fr and kinematic hardening of the same alloy, in two directions of loadings, axial and shearing ones.

The mechanism of fatigue damage in metallic materials is generally attributed to the effect of initiation and growth of micro-defects, which is usually reflected by degradation of macroscopic properties [17]. The micro-voids and the micro-cracks are two frequent micro-defects in metals. The nucleation, the coalescence and the propagation of these micro-defects are the predominant mechanisms in metals fatigue damage [18]. In addition to recent experimental investigations on fatigue damage, numerical simulations of cyclic damage evolution have been developed in recent years [19-25]. In most cases, some theoretical models describing the nucleation and propagation of micro-defects were verified either experimentally or numerically [26-30]. In continuum fatigue damage mechanics (CDM), the constitutive equations of fatigue damage models were often established on the basis of thermodynamics formulations $[31,32]$. $\mathrm{CDM}$ had not provided much information about the detailed microstructural mechanism of damage; instead, it focused on modelling the macroscopic effect of damage. Therefore, a dissipation potential parameter usually needs to be defined and constructed to establish the constitutive equations [32]. This dissipation potential should be different for various materials and/or different types of cyclic fatigue damage [33]. On one hand, the construction of an appropriate dissipation potential is not an easy task to accomplish. On the other hand, the constitutive and cyclic damage evolution equations 
may also be established experimentally using typical tests. For the phenomenological approach, a basic theoretical framework has been formed [34-36].

The modelling of anisotropic behaviour in cyclic loading of metallic materials has also been investigated many years ago [37-41]. This anisotropy was studied on several aspects; some authors have investigated its effect on the cyclic behaviour, essentially for the aluminium alloys $[1,42,43]$. Others have tried to show the importance of this anisotropic behaviour and its consideration in design of structures [44-46]. Furthermore, modelling of anisotropic behaviour in aluminium alloys has attracted extensive attention of many researchers due to its complexity and its effect on predicting fatigue damage behaviours [47-49]. With other ideas, some authors have incorporated anisotropy in the simulation of cyclic behaviours [50-52].

Keeping the importance of such behaviour in view, the microstructural investigations have been taken up by several researchers [40,53-55]. Following the ideas of some researchers who have worked in order to understand the source of the anisotropic behaviour of some steels [56-58] in our work led to understanding the origins and sources of anisotropic behaviours of AA2017 aluminium alloy. First, we confirmed this anisotropy with some other models. Indeed, we have devoted this first part to quantify fatigue damage evolution. In this context, a set of cyclic tests results from the previous work of May et al [16] conducted on cylindrical specimens of AA2017 aluminium alloy were firstly used. In the second part using several means of microstructural investigations, such as Scanning Electronic Microscopy (SEM) and Electron Back Scatter Diffraction (EBSD), we have inspected the origins of this anisotropic behaviour, which is shown in depth through this paper.

Consequently, this article is divided into three sections. The first section is devoted to the experimental procedure while the second section presents a description of models chosen to evaluate fatigue damage and their results. In the last section, investigations and discussions about microstructural observations and their relationships with the anisotropic behaviour are discussed.

\section{Experimental}

\subsection{Material characterization}

The high-strength aluminium alloy considered in the present study belongs to the Al-Cu alloy family. Such alloys have been specifically designed for their useful mechanical properties in critical structural parts of aircraft. It contains copper $(\mathrm{Cu})$ as a major alloying element and its hardening is achieved by thermal aging [59]. The material used in the present work is a hot-extruded bar of AA2017 aluminium alloy, which is machined in the form of tubular specimens; its metallurgical state and chemical composition are taken from the previous work of May et al [16].

\subsection{Description of the tests performed}

The procured cyclic tests have been performed under stress control, using a mechanical servo-hydraulic MTS-809 testing machine (maximum force of $225 \mathrm{kN}$ ). An axial-torsional extensometer with gauge length of $25 \mathrm{~mm}$ (attached to external surface of specimen) was used to measure the displacement and the rotation close to the region of interest with high resolution. All cyclic tests have been conducted at room temperature with triangular loading steps and frequency of $0.5 \mathrm{~Hz}$ in fully reverse control stress amplitude $(R=-1)$. All the tests have been conducted with a permanent cooling of the specimens. Indeed, in order to get rid of heating induced by plastic deformation process, a flow of fresh compressed air was ensured on specimens. For additional details, the reader is referred to the work of May et al [16]. However, it seems important to remind in table 1 the list of the cyclic tests performed in their works and partially used in the current study (only $\pm 280 \mathrm{MPa}$ in axial loading and $\pm 130 \mathrm{Nm}$ in torsional loading, mentioned in bold characters). Additionally, note that equivalent shear amplitudes are deducted using the Von Mises criterion (table 1).

Using the Von Mises criterion, we evaluated the equivalent stress in shear load and we obtained that the test load referenced as sh130 was comparable to axial load referenced

Table 1. List of the tests mentioned and used in the current study.

\begin{tabular}{|c|c|c|c|c|}
\hline \multicolumn{2}{|c|}{ Axial tests } & \multicolumn{3}{|c|}{ Shearing tests } \\
\hline$\sigma_{z z}(\mathrm{MPa})$ & Referenced as & $\sigma^{\mathrm{eq}}(\mathrm{MPa})$ & Torque $(\mathrm{Nm})$ & Referenced as \\
\hline \pm 240 & $\operatorname{ax} 240$ & \pm 170 & 80 & $\operatorname{sh} 80$ \\
\hline \pm 260 & $\operatorname{ax} 260$ & \pm 190 & 90 & $\operatorname{sh} 90$ \\
\hline \pm 280 & $\operatorname{ax} 280$ & \pm 211 & 100 & $\operatorname{sh} 100$ \\
\hline \pm 300 & ax300 & \pm 235 & 110 & $\operatorname{sh} 110$ \\
\hline \pm 320 & $\operatorname{ax} 320$ & \pm 256 & 120 & $\operatorname{sh} 120$ \\
\hline \pm 340 & $\operatorname{ax} 340$ & \pm 277 & 130 & $\operatorname{sh} 130$ \\
\hline \pm 360 & $\operatorname{ax} 360$ & & & \\
\hline
\end{tabular}

Here $\sigma_{z z}$ is the maximum stress applied in tension-compression direction and $\sigma^{\text {eq }}$ is the equivalent maximum shearing stress. 
as ax280. Therefore, from all the tests showed in table 1, we have considered only two tests chosen previously to be compared in this work.

\section{Description of models chosen to evaluate fatigue damage}

The mechanical fatigue damage can be defined with a dimensionless parameter $D$ as follows [10]:

$$
D=\frac{S_{D}}{S_{0}}
$$

where $S_{0}$ is the initial area without damage (virgin state of specimen). $S_{D}$ is the new area generated by all microcracks and cavities as shown in figure 1 . It is worth mentioning that the dimensionless parameter $D$ takes values in the interval $[0,1]$.

\subsection{Case of Chaboche model}

Among different possible methods used to compute ductile damage evolution in a metal subjected to cyclic loadings, a suitable non-destructive procedure is that related to the variation of material stiffness $E$, due to diminution of the initial area as shown in figure 1a, which is explained well in the work of Celentano and Chaboche [19]. In order to use this procedure, either tension or shear cyclic tests are needed to assess this diminution at high levels of deformation, in slope change corresponding to elastic response during the unloading.

In this case, Chaboche's model has allowed us to assess the evolution of fatigue damage variable $D$ for each unloadreload tensile cycle $i$ :

$$
D_{i}=1-\frac{E_{i}}{E_{0}} .
$$

The obtained results for each fatigue loading test are represented as a curve.

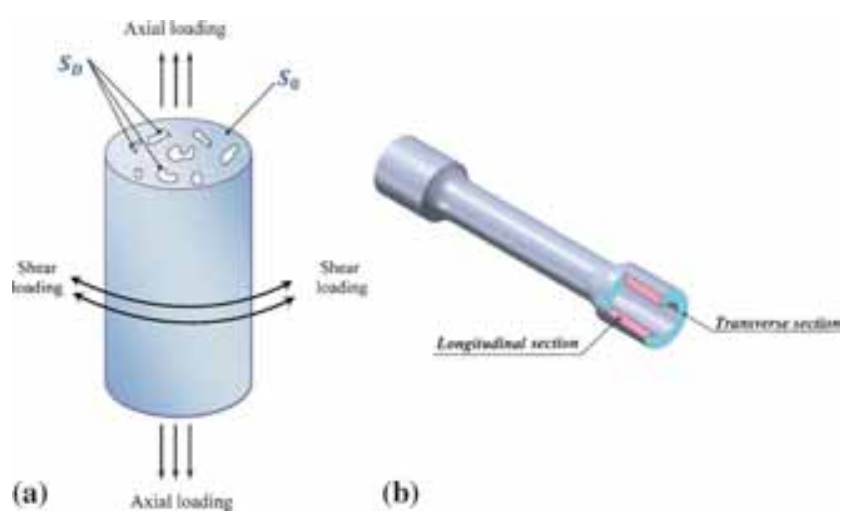

Figure 1. Terminology of the terms used in this study: (a) loading directions and surfaces used to define the fatigue damage and (b) sections used in microstructural investigations (longitudinal and transverse sections).

\subsection{Case of Henry model}

In addition to cyclic evolution of stiffness, other writers have used another procedure to evaluate mechanical fatigue damage [60]. They have associated the fatigue damage evolution of material with its fatigue limit of endurance. The instantaneous limit of endurance, suggested by Henry, is given in the following equation $[13,60]$ :

$$
\sigma_{D}=\frac{\sigma(1-r)}{\left(\sigma-\sigma_{D_{0}} / \sigma_{D_{0}}\right)+(1-r)}=\frac{\sigma(1-r)}{\gamma-r},
$$

where $r=n / N_{r}$ is the fraction of fatigue life with $\sigma$ loading and $\gamma=\sigma / \sigma_{D_{0}}$ is the overload factor with $\sigma$ loading.

Using these conditions, the fatigue damage variable $D$ can be assessed for each cycle $i$ :

$$
D_{i}=\frac{r_{i}\left(\gamma_{i}-1\right)}{\gamma_{i}-r_{i}}
$$

It is noteworthy to point out that the oldest model of Miner, used in order to quantify fatigue damage, is still usable in different classical studies. It has an advantage of simplicity to use it because it needs only the actual $\left(N_{i}\right)$ and total $\left(N_{r}\right)$ number of cycles. The fatigue damage variable $D$ can be computed for each cycle $i$ :

$$
D_{i}=\frac{N_{i}}{N_{r}} \text {. }
$$

\subsection{Case of Shanley model}

In this model, we assume that cyclic loadings lead to the formation of cracks from slip bands. Indeed, fatigue damage can be expressed by the evolution of crack length under cyclic loading:

$$
L=L_{0} \sigma_{i}^{t} e^{-w \sigma^{t} n_{i}},
$$

where $L_{0}$ is the initial size of the crack, $w$ and $t$ are some material parameters that can be deduced from the Wöhler curve.

Therefore, the evolution of fatigue damage is given by Shanley model (equation (7)). It expresses the nonlinearity of fatigue damage evolution and it is easy to implement, since there is no particular parameter to be deduced and it requires only the Wöhler curve.

$$
D_{i}=\left(e^{w \sigma^{t}\left(N_{r}-n_{i}\right)}\right)^{1-\frac{1}{r_{i}}} .
$$

Figure $2 \mathrm{a}$ and $\mathrm{b}$ shows the experimental result for the evolution of number of cycles to fracture according to stress levels. It allows us to determine the two material parameters in Shanley's model. To do this, we have to solve the following equation system using linear interpolations and the same figures (figure $2 \mathrm{a}$ and $\mathrm{b}$ ):

$$
\left\{\begin{array}{l}
N_{r i}=1 / w \sigma_{i}^{t} \\
N_{r i}=1 / w_{0} \tau_{i}^{t_{0}}
\end{array} .\right.
$$



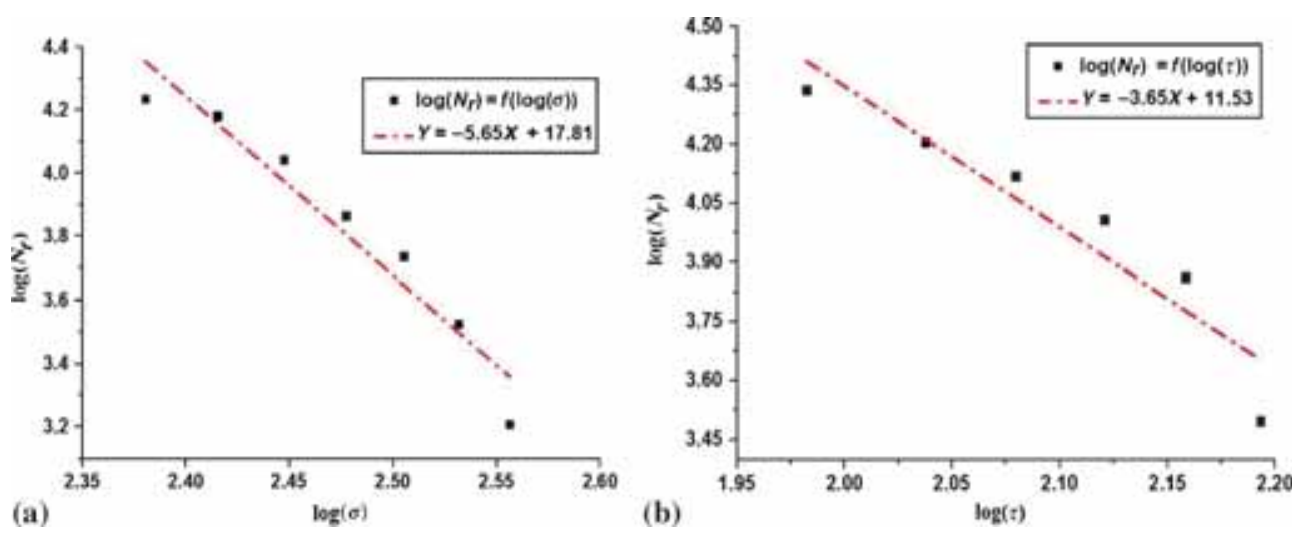

Figure 2. Evolution of the number of cycles to rupture according to stress levels: (a) in axial cyclic loading and (b) in shear cyclic loading.

Table 2. Identified parameters of the Shanley model and the Ellyin model.

\begin{tabular}{lllll}
\hline Model & \multicolumn{2}{c}{ Axial loading } & \multicolumn{2}{c}{ Torsional loading } \\
\hline \multirow{3}{*}{ Shanley } & $w$ & $t$ & $w$ & $t$ \\
& $1.84 \times 10^{-8}$ & 5.65 & $9.83 \times 10^{-6}$ & 3.58 \\
Ellyin & $A$ & $\alpha$ & $A$ & $\alpha$ \\
& 13.18 & 0.4 & 198 & 0.3 \\
\hline
\end{tabular}

The obtained results of the identified parameters are given in table 2 .

\subsection{Case of Ellyin model}

In this model, the total energy $\left(W_{\mathrm{t}}\right)$ dissipated to break the specimen had been evaluated. As shown in the work of Golos and Ellyin [61], the endurance limit $\left(N_{D}\right)$ was assigned to the cycles to failure $\left(N_{r}\right)$. Obviously, this assimilation is possible since all the tests carried out were performed until failure. To evaluate fatigue damage, the following model of Ellyin is used:

$$
D_{i}=\left(\frac{n_{i}}{N_{r i}}\right)^{\frac{\log \left(\Delta W_{i} / \Delta W_{\mathrm{s}}\right)}{\log \left(n_{i} / N_{D}\right)}},
$$

where $W_{\mathrm{s}}=A N_{r}^{\alpha-1}$ is the dissipated energy of stabilized loop, which is evaluated using its area. This allowed us to deduce the material parameters $A$ and $\alpha$ of two directions of loadings (figure $3 a$ and $b$ ). The obtained results are given in table 2 .

\subsection{Case of Bui-Quoc}

This model is based on the idea that fatigue damage accumulation results in reducing endurance limit of the material during cyclic loading. Furthermore, the decrease of endurance limit according to evolution of number of cycles follows the equation [62]

$$
\frac{\mathrm{d}\left(\frac{\sigma_{D}}{\sigma_{D_{0}}}\right)}{\mathrm{d} N}=-\frac{1}{a}\left(\frac{\sigma_{D}}{\sigma_{D_{0}}}\right)^{b}\left(\frac{\sigma}{\sigma_{D_{0}}}-\frac{\sigma_{D}}{\sigma_{D_{0}}}\right)^{2},
$$

where $a$ and $b$ are some material parameters.

To obtain fatigue damage evolution, the following conditions have to be satisfied:

$\sigma_{D}=\sigma_{D_{0}}$ in the initial state and $\sigma_{D}=\sigma_{D_{0}}\left(\sigma / R_{m}\right)^{m}$ in the last cycle, just before the fracture of specimen. We also note that the material parameter $m$ is often taken close to 8 for all aluminium alloys [13]. In this work, we also take $\sigma_{D_{0}}=$ $0.35 R_{m}$ for axial loading and $\tau_{D_{0}}=0.35 \tau_{m}$ for shearing one [13].

Consequently, the expression for fatigue damage is given as

$$
D_{i}=\frac{n_{i} / N_{r}}{1+\left(\frac{\sigma_{i}-\sigma_{D_{0}}\left(\sigma_{i} / R_{m}\right)^{m}}{\sigma_{i}-\sigma_{D_{0}}}\right)\left(1-\frac{n_{i}}{N_{r}}\right)} .
$$

According to the equation (11), it is easy to confirm that the nonlinearity of fatigue damage evolution is consistent with the Bui-Quoc model and it takes into account the nature and the type of loading through the use of instantaneous endurance limit. This model can be used in all types of loadings except those below the endurance limit. However, the history of loading can be taken into account only partially. Moreover, the Bui-Quoc model needs to have mechanical resistance $\left(R_{m}\right)$ and endurance limit $\left(\sigma_{D_{0}}\right)$ of the material defined beforehand.

\subsection{Results and analyses}

In the current section, the capabilities of describing the anisotropic behaviour of AA2017 of the different models cited earlier will be discussed. As shown in the previous work of May et al [16], this aluminium alloy exhibits an 

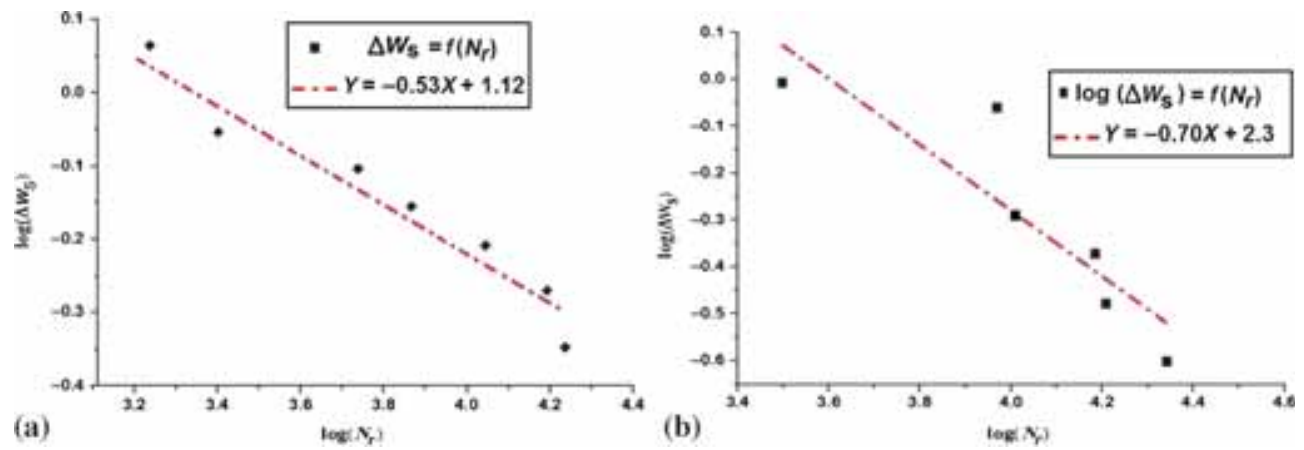

Figure 3. Evolution of the dissipated energy for stabilized loop according to the number of cycles to failure: (a) axial and (b) shear cyclic loadings.

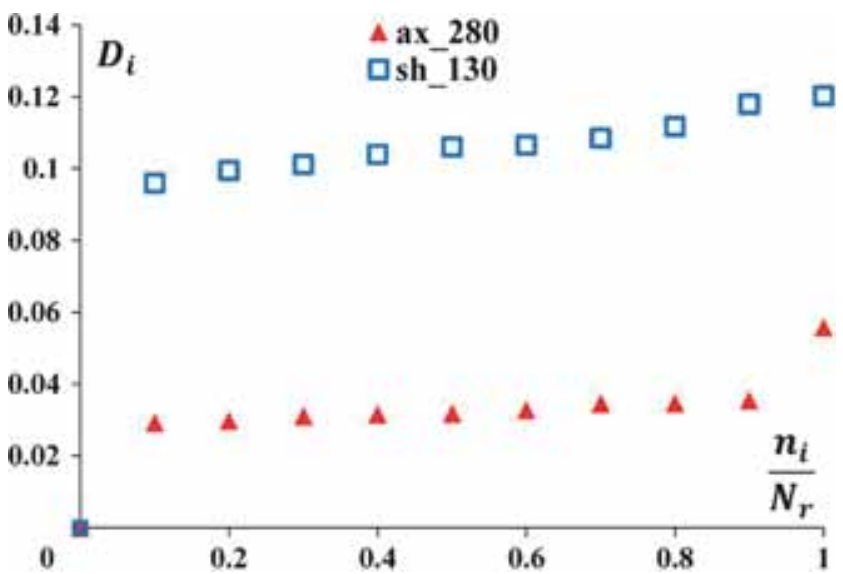

Figure 4. Evolutions of the fatigue damage using the model of Chaboche in two cyclic loadings: axial and shearing.

anisotropic behaviour based on different responses obtained in two loading directions. In the rest of this section, the predictions of each models concerning anisotropic behaviour will be discussed.

For the Chaboche model and according to the evolutions shown in figure 4, the anisotropic behaviour of the current aluminium alloy, between the axial loads and the shearing ones, may be deduced from the differences between the two curves. Additionally, according to the magnitude of fatigue damage in the shear loading, it can also be deduced that this loading is more destructive than the axial one.

For the Henry model, the obtained results are presented in figure 5. It is shown that the fatigue damage evolution seems to follow a polynomial growth from the virgin state to the fracture of specimens. However, one can notice that this model does not take into account the anisotropic behaviour of aluminium alloy. Indeed, one can observe from figure 5 that no significant differences exist between axial and shearing loadings.

For the Shanley model, the obtained results for the two cyclic loadings used in the current study are presented in figure 6. From the evolutions of the two curves presented in this figure, it can be deduced that this model takes into

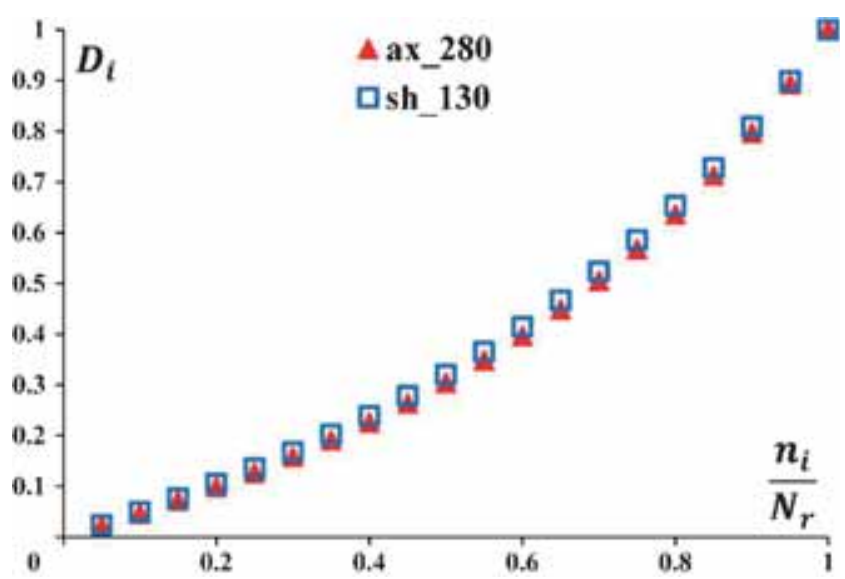

Figure 5. Evolution of the fatigue damage using the model of Henry in two cyclic loadings: axial and shearing.

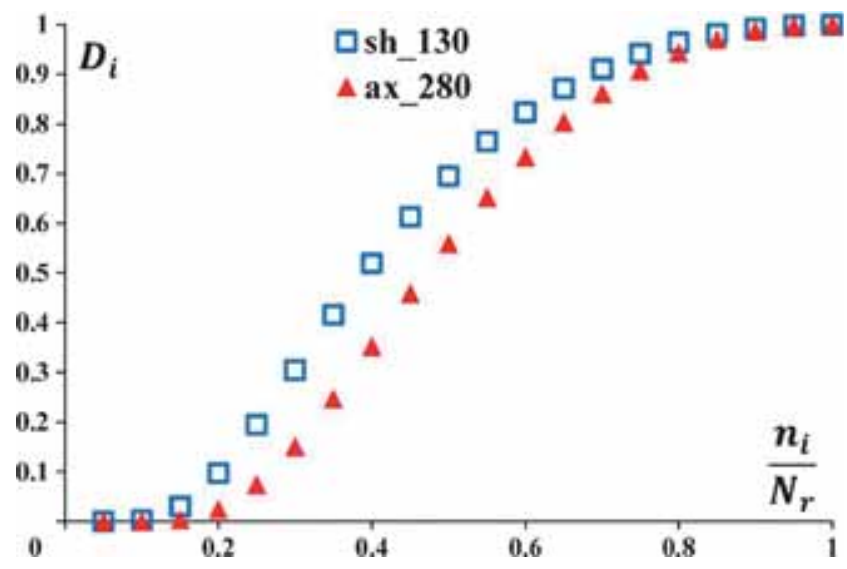

Figure 6. Evolution of the fatigue damage using the model of Shanley in two cyclic loadings: axial and shearing.

account only partially the anisotropic behaviour of aluminium alloys. Indeed, one can also mention that the two previous curves seem to be distant from one another, by 10 to $90 \%$ of the evolution of fatigue damage parameter ' $D$ '. One can conclude that, according to the Shanley model, the 
AA2017 aluminium alloy has an anisotropic behaviour but without it being widely revealed.

Regarding the Ellyin model, whose results are shown in figure 7 , one can remark that fatigue damage had increased exponentially. This finding is in good agreement with its constitutive equation given in equation (9). Also, it can be noticed that this model does not detect any fatigue damage at the beginning of cyclic loading until mid-life of specimens. Even more, the anisotropic behaviour of the current aluminium alloy is not at all proven with this model.

Concerning the Bui-Quoc model, the obtained results for two cyclic loadings used to compare their mechanical behaviour are presented in figure 8 . From their evolutions, it can be noticed that when the two curves are overlaid, it can be deduced that this model does not reveal the anisotropic behaviour of aluminium alloys.

According to the previous analyses, one can infer that the anisotropic behaviour of AA2017 aluminium alloy, exhibited in fatigue damage, is revealed in Chaboche's and Shanley's models. Indeed, it can be confirmed that this aluminium alloy is an anisotropic material in mechanical behaviour. To give more weight to this confirmation, we have shown an overall

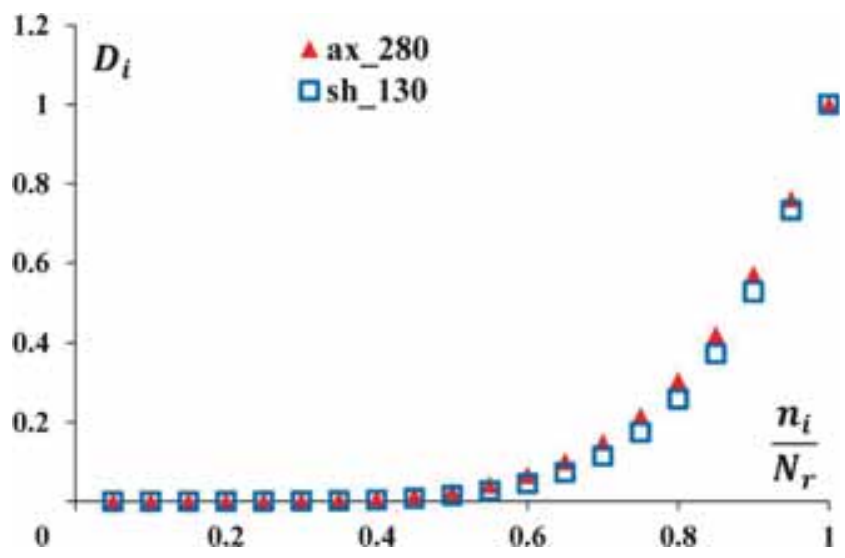

Figure 7. Evolution of the fatigue damage using the model of Ellyin in two cyclic loadings: axial and shearing.

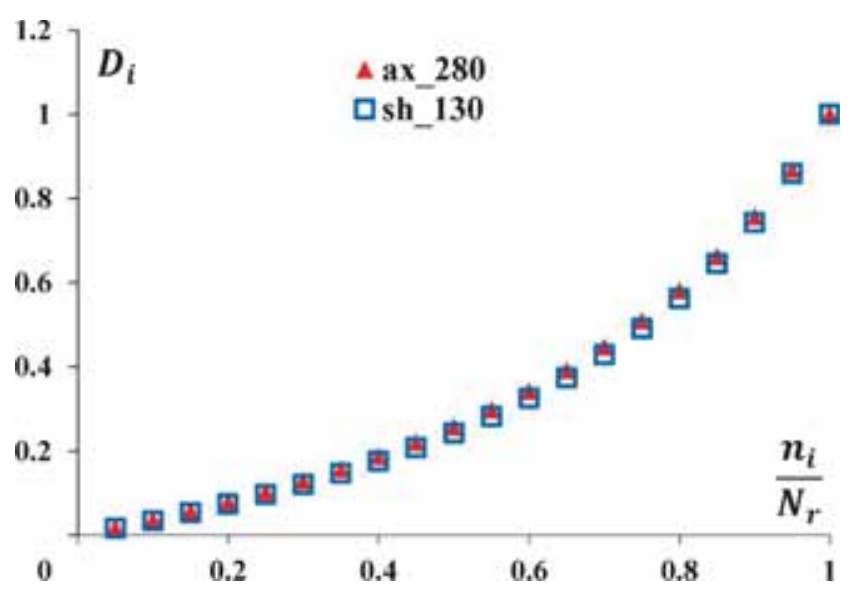

Figure 8. Evolution of the fatigue damage using the model of Bui-Quoc in two cyclic loadings: axial and shearing. comparison among the models used in this study in figures 9 and 10. In the first figure, we depict the findings of axial cyclic loading, where one can notice that the Shanley model seems to be able to predict a large evolution of fatigue damage. It began after $23 \%$ of fatigue life of the tested samples. However, in the Ellyin model, this large evolution began after $54 \%$ of fatigue life of the tested samples.

A similar study is carried out for the shear loadings, where one can deduce similar conclusions as those given for the axial tests. Figure 10 shows a comparison among the five models considered in this study for shear loading. It can be noticed that the Shanley model begins to be sensitive to fatigue damage at roughly $16 \%$ of the fatigue damage life. However, the Ellyin model is insensitive to fatigue damage even until the completion of $55 \%$ of fatigue damage life.

In order to understand the macroscopic behaviour of the current alloy, one have to explore the structure of the alloy at a microscopic scale. This is the second main objective of this paper and will be dealt with in the next section.

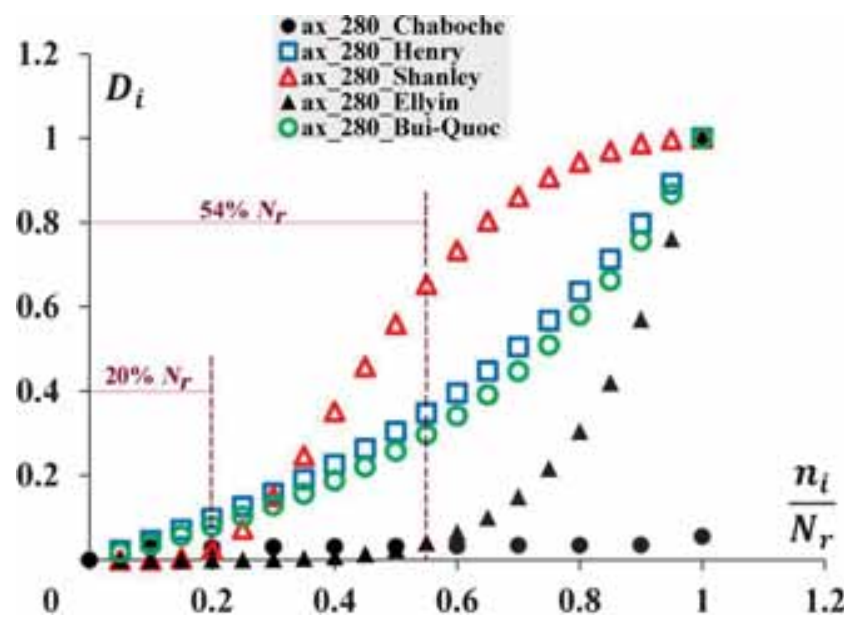

Figure 9. Comparison among the fatigue damage evolutions obtained in axial cyclic loading using different models.

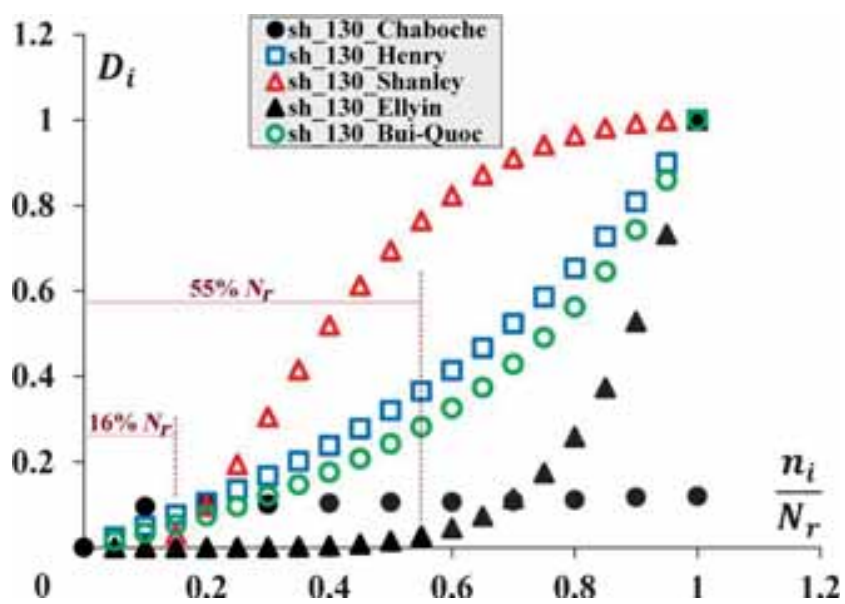

Figure 10. Comparison among the fatigue damage evolutions obtained using different models in shear cyclic loading. 


\section{Microstructural investigations}

In this section, some experimental investigations carried out are summarized in order to understand the true origins of the anisotropic behaviour of AA2017 aluminium alloy. To do this, we have analysed the microstructural texture of the alloy using SEM. The analysed samples were taken from cylindrical specimens similar to those used in fatigue damage tests and they were machined by extrusion. Indeed, three samples were taken from three different locations of cylindrical specimen used in cyclic loading. The last is taken from the batch of samples used in May et al [16].

These investigations were performed using a detector coupled with Aztec Oxford Instruments software. However, before analysing the samples and in order to have sharper mapping, their surfaces must be prepared. To do this, one must first perform mechanical polishing followed by electrolytic polishing. To identify the phases of the studied material, a high-resolution EBSD detector $(1344 \times 1024)$ at a frequency of $110 \mathrm{~Hz}$ was used in these investigations.

Note that the metallurgical state of the samples used in this study was T3. To obtain that state, the samples were heated until $500^{\circ} \mathrm{C}$ and maintained at that temperature for $1 \mathrm{~h}$. After that, they were quenched in icy water and naturally aged for $24 \mathrm{~h}$ at room temperature.

\subsection{Identification of the phases}

Identification of the phases does not depend on crystallographic directions of material's texture, or the locations where samples are taken from. Figure 11a and b shows two types of images obtained using the Forward-Scatter EBSD detector. The sample analysed was taken from a longitudinal section presented in figure $1 \mathrm{~b}$.

Chemical analysis, in order to find the nature of the constituent phases, has been performed at several sites of the SEM micrographs shown in figure 11a. As the first step, the alpha phase was analysed. It looks like a grey region of solid solution where some copper atoms have been dissolved in a matrix of aluminium atoms. This phase appears like a homogeneous aluminium-copper system and seems to have uniform physical and chemical characteristics. The obtained results are shown in figure 12 .

Crystallographic analysis of the samples taken from longitudinal section has been performed using a phosphoric fluorescent screen upon impact by backscattered electron. An EBSD pattern is formed when electrons from several different planes diffract to form the Kikuchi lines, corresponding to each diffraction plane. Using the illustrations given in figure 12 and according to the chemical analysis, we have deduced that the alpha phase is essentially composed of pure aluminium and some traces of copper and magnesium. In the second step and using the same method, we have likewise analysed all the visualized phases shown in figure 11 . The obtained results are shown in figure 12. The amounts of $\mathrm{Al}_{2} \mathrm{Cu}$ precipitates are not fairly significant, because of the type of heat treatment performed to samples. From the same figure, we have deduced that the dark grey precipitates shown with yellow circle in figure 13 were crystallized as $\mathrm{Mn}_{2}(\mathrm{Al}, \mathrm{Si})$ system. The light grey (or white back curtain) precipitates shown with blue circle in the same figure are crystallized in the form of a defined compound $\mathrm{Al}_{2} \mathrm{Cu}$. The dark precipitates shown with yellow circle are crystallized in the form of a defined compound $\mathrm{Mg}_{2} \mathrm{Si}$. It can also be confirmed, using the very clearly obtained Kikuchi diagrams, that the material used in this study is low in impurities and grain boundaries.

\subsection{Texture analyses}

Using the EBSD images (IPF map), acquired through scanning the same zone given in figure 12 and taken from a longitudinal section, we have obtained the distribution shown in figure 14. One can remark that most grains are oriented in $\langle 111\rangle$ direction. However, the average grain size estimated in this analysed section is only about $9 \mu \mathrm{m}$.

Another feature that can be drawn from this analysis is the extension of grains in the longitudinal direction; it corresponds to the extrusion direction of rods used to manufacture samples. This phenomenon leads to prediction of anisotropic

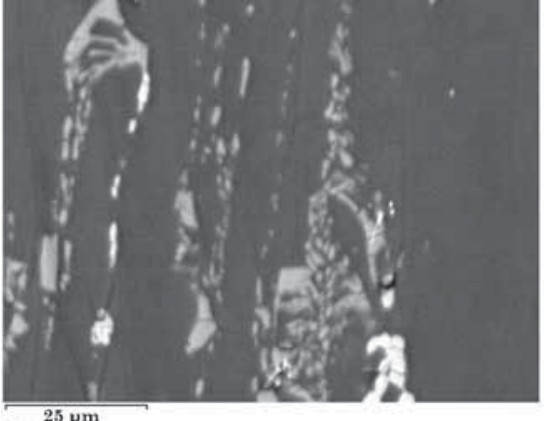

(a)

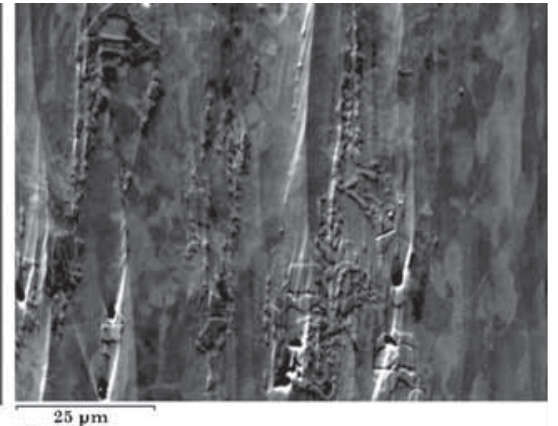

(b)

Figure 11. Illustrations of phases obtained with a longitudinal section: (a) the phases are obtained by chemical contrast difference and (b) the phases are obtained using a topographic contrast. 


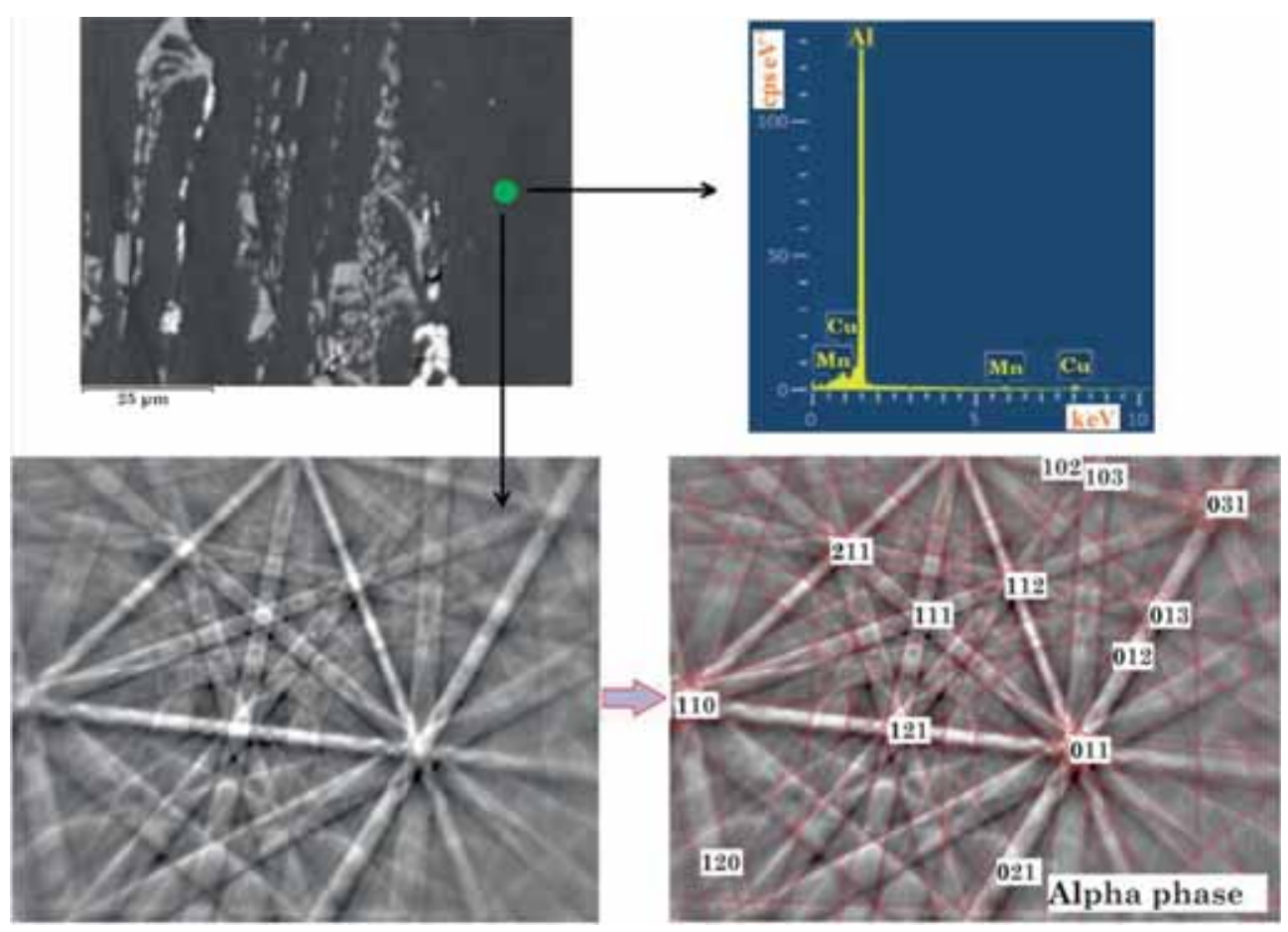

Figure 12. Illustration of location where chemical and crystallographic analyses were performed for alpha phase.

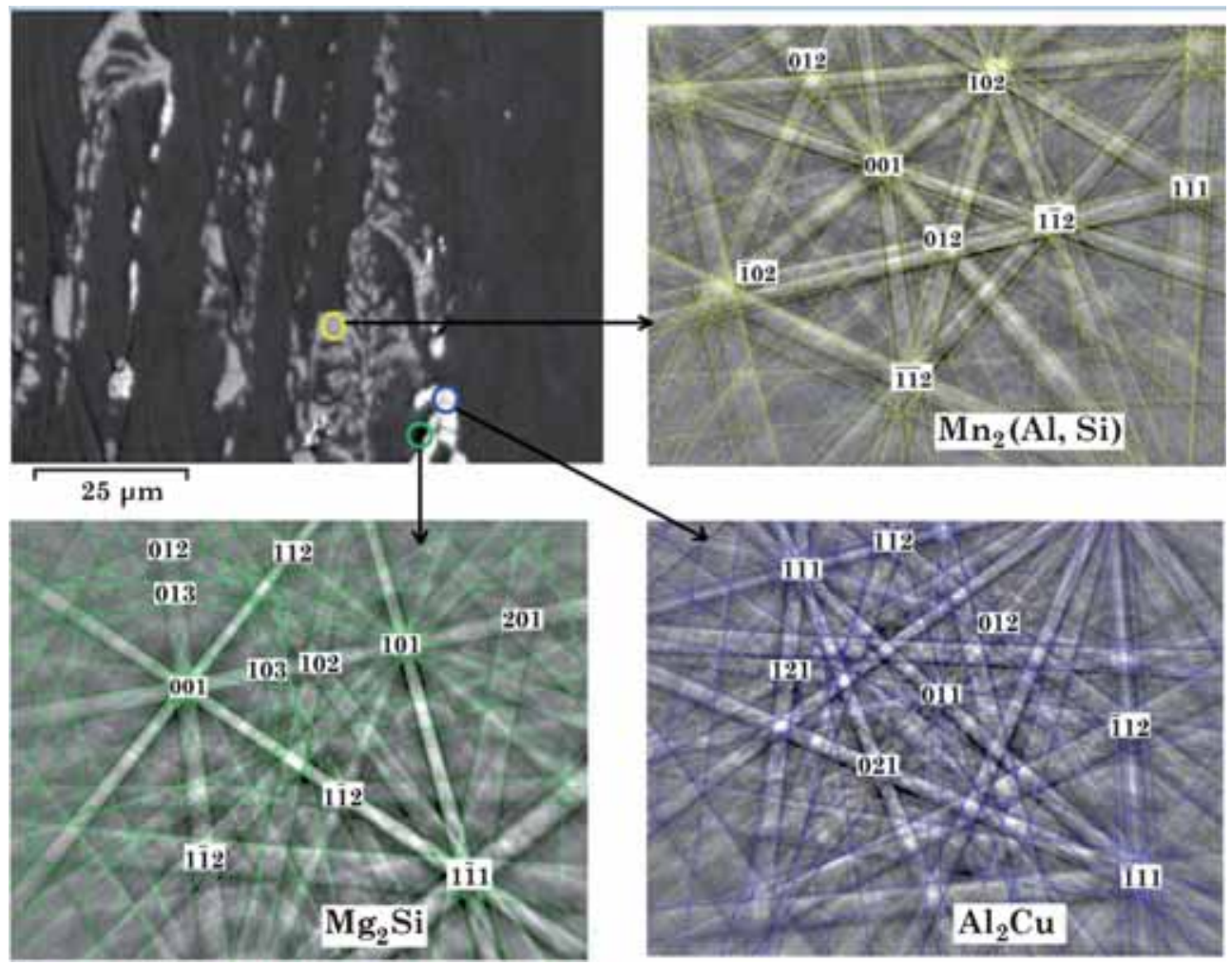

Figure 13. Illustration of the locations and identification of the different phases analysed using chemical and crystallographic processes. 

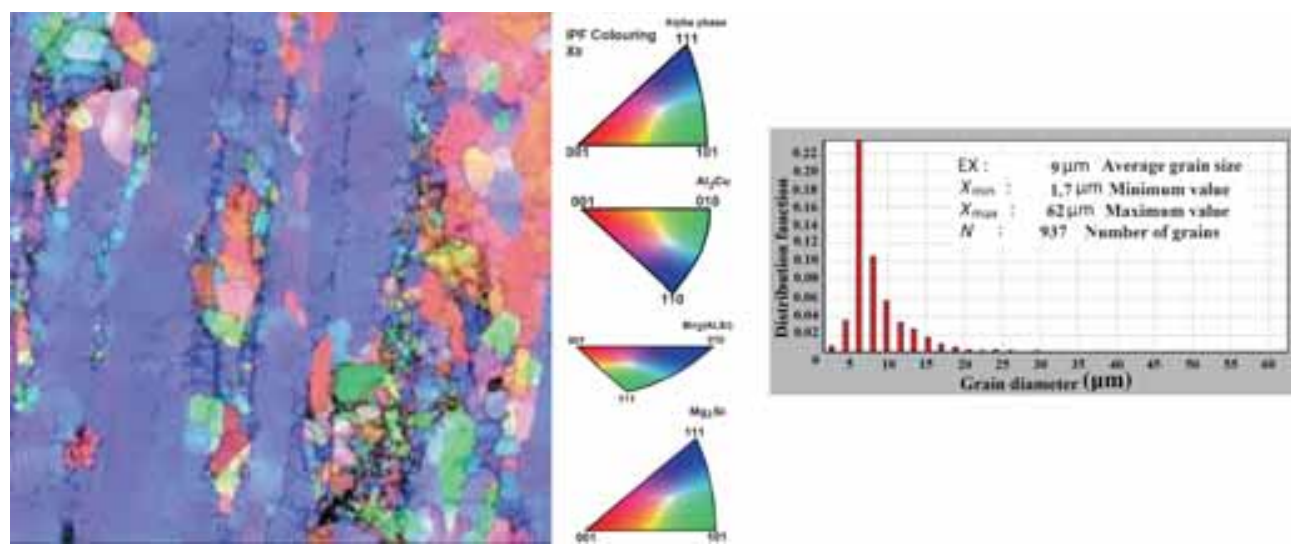

Figure 14. Microstructures of the transverse section and its grains size distribution for AA2017 aluminium alloy.

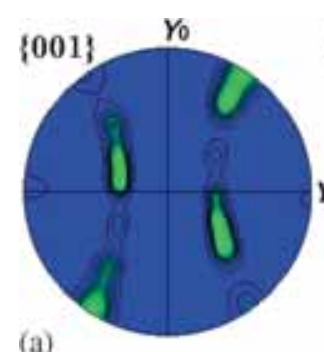

(a)

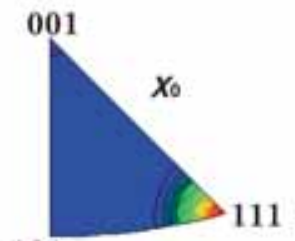

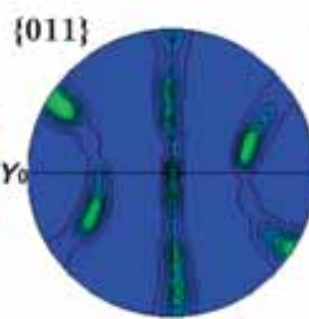

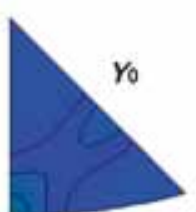

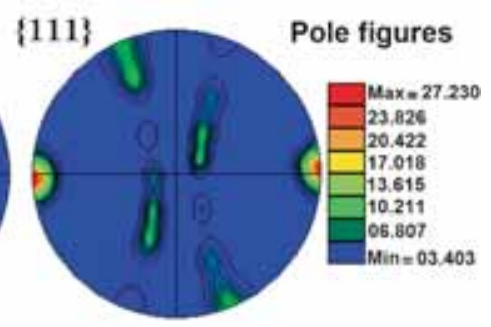

Inverse pole figures

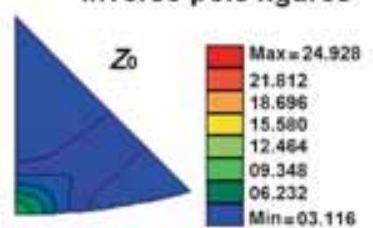

(b)

Figure 15. Crystallographic textures analysis on AA2017 aluminium alloy by EBSD: (a) pole figures of $\{111\},\{001\}$ and $\{011\}$ planes and (b) inverse pole figures of $\{111\}$ plane.
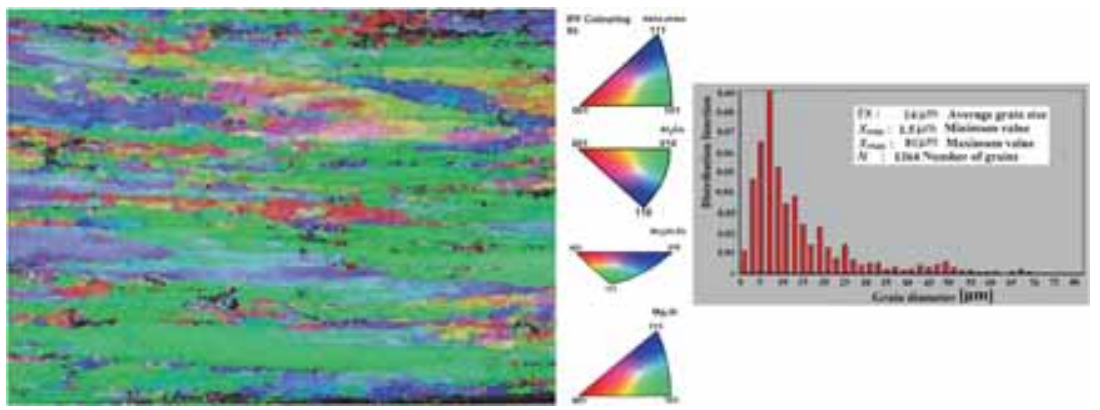

Figure 16. Microstructures of the longitudinal section and its grains size distribution for AA2017 aluminium alloy.

behaviour in that direction compared with the transverse one. It also allows to say that the analysed grains are textured. Besides, to further confirm this contention, the pole figures of the principal planes $\{011\}$ and $\{111\}$ have been analysed. The obtained results are shown in figure 15 . One notices that the maximum pole density is slightly elevated for $\{111\}$ plane; it shows more than 27 m.r.d. (multiple random densities).

In other words, the results shown in the inverse pole figures of $\{111\}$ plane given in figure 15 demonstrate that the fibres of AA2017 aluminium alloy are elongated in the 

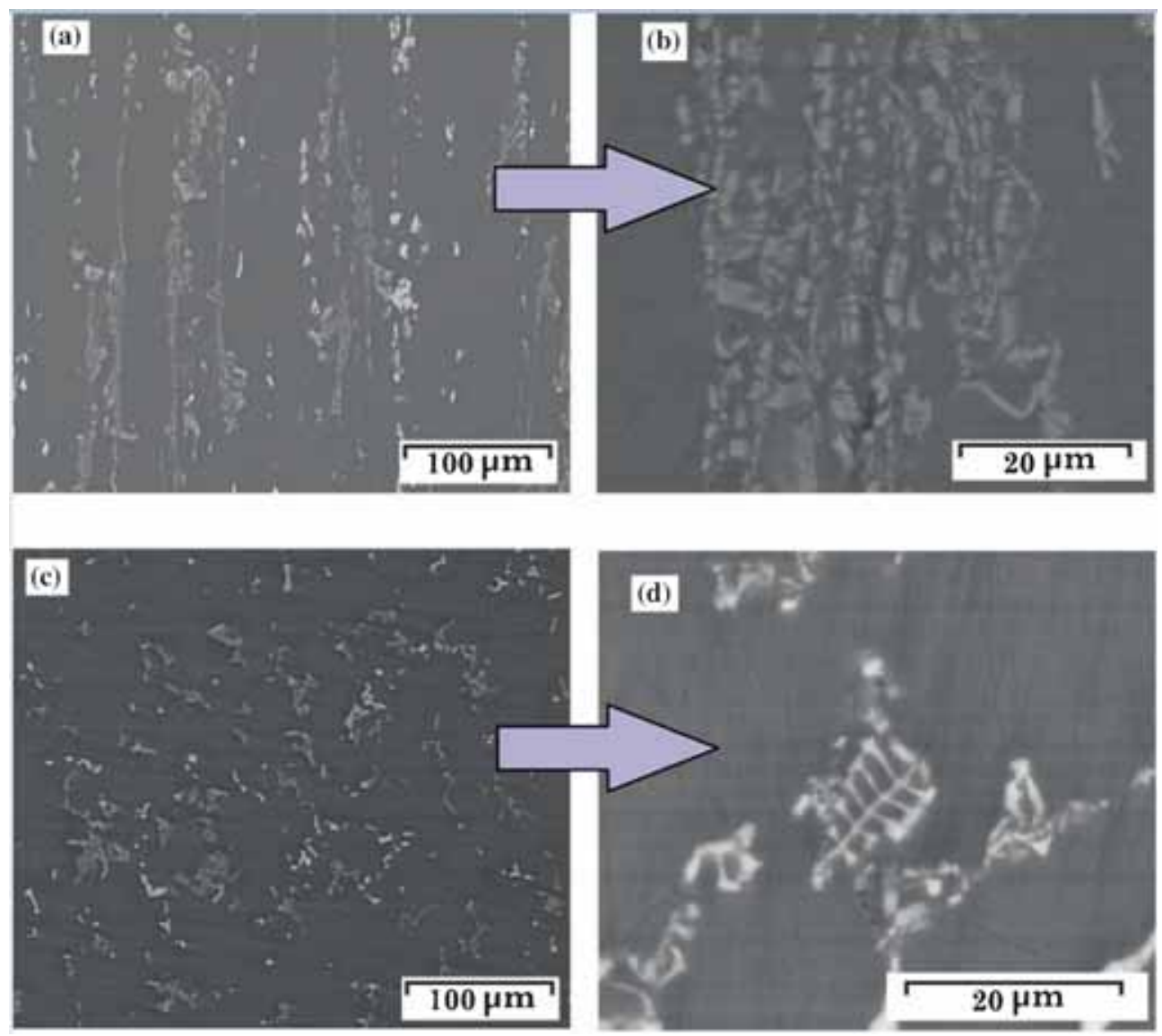

Figure 17. SEM micrographs for extruded AA2017 aluminium alloy: (a, b) with two different magnifications from longitudinal section and $(\mathbf{c}, \mathbf{d})$ with two different magnifications from transverse section.

direction of extrusion given by random density direction in $\{111\}$ plane. These findings suggest preferential crystallographic directions which lead to mechanical material anisotropy.

To confirm these conclusions, the longitudinal section (figure 1b) was analysed. Indeed, the same investigations were performed using the same methods. The obtained results show that the average grain size is strongly higher than one obtained in transverse section and it is about $14 \mu \mathrm{m}$ (an estimated increase of around 55\%). The origin of this elongation can be attributed to the intense plastic deformation during extrusion. We have illustrated the obtained results in figure 16 .

In order to illustrate these differences between the two analysed directions and understand its effect on macroscopic cyclic behaviour more, we examined two SEM images taken from the longitudinal and the transverse sections and compared them. In figure 17, we have shown the micrographs taken from the longitudinal section in figure $17 \mathrm{a}$ and $\mathrm{b}$. In addition, the micrographs taken from the transverse section are shown in figure $17 \mathrm{c}$ and $\mathrm{d}$. On analysing these micrographs, one notices that all precipitates (essentially $\left.\mathrm{Mn}_{2}(\mathrm{Al}, \mathrm{Si})\right)$ are elongated in the direction of material extrusion. Using a greater magnification (see figure $17 \mathrm{~b}$ and $\mathrm{d}$ ), one notices that these precipitates are broken into small pieces produced by the strong force during extrusion.

However, the micrograph in figure $17 \mathrm{c}$ taken from the transverse section seems to show an homogenous distribution of precipitates and without distortion. With the greater magnification in figure $17 \mathrm{~d}$, one notices that these precipitates were not elongated by the extrusion operation and not broken by the stretching stress. These findings can also confirm the microstructural anisotropy, which is the cause of the differences obtained in cyclic loading behaviour of AA2017 aluminium alloy.

\section{Concluding remarks}

In this work, we have investigated the origins of the anisotropic mechanical behaviour of AA2017 aluminium alloy. This phenomenon has already been observed and deduced from previous works, where a series of cyclic loadings have been performed on the same extruded aluminium alloy at room temperature. Indeed, it was deduced that the current material exhibits anisotropic behaviour of fatigue damage in axial and shear directions. In the first part and in order to confirm this anisotropic behaviour, different models 
of fatigue damage evolution have been implemented in order to quantify the evolution of fatigue damage. On one hand, some models have confirmed the anisotropic mechanical behaviour of AA2017 aluminium alloy. In this case, the model of Chaboche takes into account this singularity of the present material. On other hand, the model of Shanley takes into account this anisotropic behaviour only partly, from 10 to $90 \%$ of fatigue damage life. However, the models of Henry, Ellyin and Bui-Quoc were not able to take into account this anisotropic mechanical behaviour of AA2017 aluminium alloy.

In the second part, to explore the texture and the microstructure of our material, some microstructural investigations have been carried out on samples extracted from the tested specimens. The specimens were taken from the longitudinal and the transverse sections and analysed using EBSD/EDS coupled to SEM. The obtained results show significant differences between the two analysed surfaces. These differences, which seem to be the origins of the anisotropic behaviour of AA2017 aluminium alloy, might be due to physical transformations caused by the extrusion operation on the material. The SEM micrographs of longitudinal surfaces showed that the extrusion of material had elongated the precipitates in its direction until it had fragmented them into small and broken pieces. However, the micrographs of the transverse surface showed that its precipitates were not transformed by the extrusion. Thus, these differences in the morphologies of the precipitates can cause a big anisotropic behaviour between the two directions of loadings: longitudinal and transversal. Specifically, using the EBSD analysis, we have demonstrated that the average grain size in longitudinal section is $14 \mu \mathrm{m}$; however in transverse section it is only $9 \mu \mathrm{m}$. Also, using the poles figures, we have confirmed that the current aluminium alloy is textured. These are the origins of the anisotropic behaviour of AA2017 aluminium alloy.

\section{Acknowledgements}

The author acknowledges the French Team of Oxford Instrument for their grateful help in releasing the EBSD/EDS analyses using their best material resources.

\section{References}

[1] Bois-Brochu A, Blais C, Goma F A T, Boselli J and Brochu M 2014 Mater. Sci. Eng. A 62597

[2] Immarigeon J P, Holt R T, Koul A K, Zhao L and Beddoes J C 1995 Mater. Charact. 3541

[3] May A, Belouchrani M A, Taharboucht S and Boudras A 2010 Proc. Eng. 21795

[4] Williams J C and Starke E A Jr 2003 Acta Mater. 515775

[5] May A, Belouchrani M A, Manaa A and Bouteghrine Y 2011 Proc. Eng. 10798

[6] Moy C K S, Weiss M, Xia J, Sha G, Ringer S P and Ranzi G 2012 Mater. Sci. Eng. A 48552
[7] Bouzaiene H, Rezgui M A, Ayadi M and Zghal A 2012 Trans. Nonferr. Met. Soc. 221064

[8] Araújo D, Carpio F J, Méndez D, García A J, Villar M P, García R, Jiménez D and Rubio L 2003 Appl. Surf. Sci. 208 210

[9] Carpio F J, Araújo D, Pacheco F J, Méndez D, García A J, Villar M P, García R, Jiménez D and Rubio L 2003 Appl. Surf. Sci. 209194

[10] Zhang L, Liu X S, Wang L S, Wu S H and Fang H Y 2012 Trans. Nonferr. Metal. Soc. 222777

[11] Kluger K 2015 Int. J. Fatigue 2280

[12] Kluger K and Łagoda T 2014 Int. J. Fatigue 66229

[13] Taharboucht S, Aberkane A and May A 2016 Thesis p 62

[14] Mayer H, Papakyriacou M, Pippan R and Stanzl-Tschegg S 2001 Mater. Sci. Eng. A 48314

[15] Kofto D G 1990 Strength Mater. 22283

[16] May A, Taleb L and Belouchrani M A 2013 Mater. Sci. Eng. A 123571

[17] Le V-D, Morel F, Bellett D, Saintier N and Osmond P 2016 Mater. Sci. Eng. A 426649

[18] Pineau A, Amine Benzerga A and Pardoen T 2016 Acta Mater. 107508

[19] Celentano D J and Chaboche J-L 2007 Int. J. Plast. 231739

[20] Djebli A, Aid A, Bendouba M, Amrouche A, Benguediab M and Benseddiq N 2013 Int. J. Nonlin. Mech. 51145

[21] Chaboche J L 1987 Nucl. Eng. Des. 19105

[22] Chaboche J L 1989 Int. J. Plast. 5247

[23] Wang C, Wang X, Ding Z, Xu Y and Gao Z 2015 Int. J. Fatigue $\mathbf{1 1} 78$

[24] Aid A, Amrouche A, Bouiadjra B B, Benguediab M and Mesmacque G 2011 Mater. Des. 32183

[25] Nouailhas D, Chaboche J L, Savalle S and Cailletaud G 1985 Int. J. Plast. 1317

[26] Walvekar A A, Leonard B D, Sadeghi F, Jalalahmadi B and Bolander N 2014 Tribol. Int. 79183

[27] Thionnet A, Chambon L and Renard J 2002 Int. J. Fatigue 24 147

[28] Lukáš P, Jardin A, Leblond J-B, Berghezan D and Portigliatti M 2010 Proc. Eng. 21643

[29] Szusta J and Seweryn A 2011 Int. J. Fatigue 33255

[30] Trebuňa P F, Sága M, Kopas P and Uhríčík M 2012 Proc. Eng. 48599

[31] Lemaitre J 1985 Comput. Meth. Appl. Mech. Eng. 5131

[32] Chak-yin T, Jianping F, Chi-pong T, Tai-chiu L, Luen-chow C and Bin R 2007 Acta Mech. Solida Sin. 2057

[33] Kim D, Dargush G F and Basaran C 2013 Eng. Struct. 52608

[34] Shen F, Hu W and Meng Q 2016 Int. J. Fatigue 90125

[35] Kauppila P, Kouhia R, Ojanperä J, Saksala T and Sorjonen T 2016 Proc. Struct. Integrity 2887

[36] Jiang M 1995 Eng. Fract. Mech. 52971

[37] Crooks R, Wang Z, Levit V I and Shenoy R N 1998 Mater. Sci. Eng. A 257145

[38] Al-Maharbi M, Karaman I, Beyerlein I J, Foley D, Hartwig K T, Kecskes L J and Mathaudhu S N 2011 Mater. Sci. Eng. A $\mathbf{5 2 8} 7616$

[39] Khan A S and Baig M 2011 Int. J. Plast. 27522 
[40] Li X, Al-Samman T and Gottstein G 2011 Mater. Des. 32 4385

[41] Cho J-H, Jae Kim W and Gil Lee C 2014 Mater. Sci. Eng. A 597314

[42] Gilles G, Hammami W, Libertiaux V, Cazacu O, Yoon J H, Kuwabara T, Habraken A M and Duchêne L 2011 Int. J. Solids Struct. 481277

[43] Joo M S, Suh D W, Bae J H, Sanchez Mouriño N, Petrov R, Kestens L A I and Bhadeshia H K D H 2012 Mater. Sci. Eng. A 556601

[44] Banumathy S, Mandal R K and Singh A K 2010 J. Alloys Compd. 26500

[45] Williams B W, Simha C H M, Abedrabbo N and Mayer R 2010 Int. J. Impact. Eng. 37652

[46] Brünig M 1995 Fin. Elem. Anal. Des. 20155

[47] Dillard T, Forest S and Lenny P 2006 Eur. J. Mech. A-Solid 25526

[48] Khadyko M, Dumoulin S, Børvik T and Hopperstad O S 2015 Comput. Struct. 1560

[49] Saï K, Taleb L and Cailletaud G 2012 Comput. Mater. Sci. 6548
[50] Dong C, Yang X, Shi D and Yu H 2014 Mater. Des. 55966

[51] Vanegas E, Mocellin K and Logé R 2011 Proc. Eng. 10 1208

[52] Garmestani H, Kalidindi S R, Williams L, Fountain C and Lee E W 2002 Int. J. Plast. 181373

[53] Wang Z-W, Yuan Y-B, Zheng R-X and Ameyama K 2014 Trans. Nonferr. Met. Soc. 242366

[54] Papasidero J, Doquet V and Lepeer S 2014 Mater. Sci. Eng. A 610203

[55] Hajizadeh K, Tajally M, Emadoddin E and Borhani E $2014 \mathrm{~J}$. Alloys Compd. 588690

[56] Zong C, Zhu G-H and Mao W-M 2013 J. Iron. Steel Res. Int. 2066

[57] Hales S J and Hafley R A 1998 Mater. Sci. Eng. A 257153

[58] Mizera J, Driver J H, Jezierska E and Kurzydłowski K J 1996 Mater. Sci. Eng. A 9421

[59] Khan S, Kintzel O and Mosler J 2012 Int. J. Fatigue 37112

[60] Henry D L 1955 Trans. Am. Soc. Mech. Eng. 77913

[61] Golos K and Ellyin F 1987 Theor. Appl. Fract. Mech. 7169

[62] Bui-Quoc T 1982 Exp. Mech. 22180 